\title{
Clinical Profile of Adult Patients Having Pulmonary Tuberculosis in Rajasthan: A Tertiary Care Centre Study
}

\author{
Authors \\ Dr Manan Bedi ${ }^{*}$, Dr R.C. Meena ${ }^{2}$, Dr Nalin Joshi ${ }^{3}$, Dr Pradeep Soothwal ${ }^{4}$, \\ Dr Devender Sharma ${ }^{5}$, Dr Vibhor Dubey ${ }^{6}$, Dr Kunal waghela ${ }^{7}$, \\ Dr Ashish Tyagi ${ }^{8}$, Dr Dharvi Hapaliya ${ }^{9}$, Dr Fasal Ul Haq ${ }^{10}$ \\ ${ }^{1}$ Post graduate resident ( $3^{\text {rd }}$ year), Department of Respiratory Medicine, NIMS, Jaipur \\ ${ }^{2}$ Professor and head, Department of Respiratory Medicine, NIMS, Jaipur \\ ${ }^{3}$ Professor, Department of Respiratory Medicine, NIMS, Jaipur \\ ${ }^{4}$ Assistant Professor, Department of Respiratory Medicine, NIMS, Jaipur \\ ${ }^{5,6}$ Senior Resident, Department of Respiratory Medicine, Jaipur \\ ${ }^{7}$ Post graduate resident ( $2^{\text {nd }}$ year), Department of Respiratory Medicine, NIMS, Jaipur \\ ${ }^{8,9,10}$ Post graduate resident $\left(1^{\text {st }}\right.$ year $)$, Department of Respiratory Medicine, NIMS, Jaipur \\ *Corresponding Author \\ Dr Manan Bedi
}

\begin{abstract}
Introduction: Tuberculosis is caused by the Mycobacterium tuberculosis Complex, this complex includes M.tuberculosis, M. microti, M. africanum, M. bovis and M. canetti. Therefore primary site of infection is lung is the most commonly involved organ. One of the leading cause for deaths among adults in the world amongst the infectious diseases is Tuberculosis which in developing world accounts for $25 \%$ of avoidable adult deaths.

Material and Method: The cross-sectional retrospective study was conducted at respiratory department of a tertiary care centre in Rajasthan, on 197 patients, where data was collected from year 2019 to 2020 from tuberculosis register maintained in tuberculosis unit .

Result: A total of 197 patients were studied who fulfilled the inclusion criteria were enrolled in this study from January 2019 to June 2020. This study was done in Department of Respiratory medicine in a tertiary care hospital, Rajasthan. 144 were male (73.1\%) and 53 were females (26.9\%). 137 (69.5\%) patients were of age group 21-40 years and only $16(8.13 \%)$ patients between $61-70$ years. 152 were of rural area $(77.2 \%)$ and 45 were of urban area (22.8\%). Cough was the most common symptom (88.0\%) followed by fever (85.7\%). Hemoptysis (38.5\%) and chest pain $(17.2 \%)$ were the next common symptoms. Heaviness of chest (3.0\%) was the least common symptom. Pulmonary infiltrate ( 55.8\%) was most common radiological finding in their chest $x$-ray, followed by cavity (29.9\%). 17 patients had nodular shadow (8.7\%) and only 11 patients had military pattern (5.6\%). 163 patients had unilateral involvement of lung (82.7\%) and only 34 cases had bilateral involvement (17.3\%). Most of the patients had right upper zone (59.8\%) involvement, followed by left upper zone (11.6\%) with involvement of lower lung field in only $4.0 \%$.

Conclusion: Pulmonary tuberculosis is a curable disease if given proper treatment at proper time. Clinician need to understand these symptoms and findings of Chest X-ray soon for better management of patients. More study need to be done including different data from various tertiary care centre for more specific details.
\end{abstract}

Keywords: Pulmonary, Tuberculosis, Chest $x$-ray, Clinical profile. 


\section{Introduction}

Tuberculosis is caused by the Mycobacterium tuberculosis Complex, this complex includes M.tuberculosis, M. microti, M. africanum, M. bovis and $M$. canetti. ${ }^{1}$ In most of the cases tuberculosis is caused by Mycobacterium tuberculosis. The route of transmission of infection is mainly respiratory is through inhalation of droplet nuclei. ${ }^{2}$ Therefore primary site of infection is lung is the most commonly involved organ. One of the leading cause for deaths among adults in the world amongst the infectious diseases is Tuberculosis which in developing world accounts for $25 \%$ of avoidable adult deaths. ${ }^{2}$ Despite the development of effective anti-tubercular drugs, tuberculosis has killed more than 100 million people over the last century. Tuberculosis is the only disease which has the designated as "Global Emergency" by WHO in 1993. Tuberculosis was described in 2003 as a continued pandemic by WHO. According to WHO, about one third of world's population is infected with mycobacterium tuberculosis. It is also considered as second killer disease worldwide after HIV-AIDS, killing nearly two million people every year. Asian countries like India, Bangladesh, Philippines, China and Pakistan have more than $50 \%$ of tuberculosis patients. ${ }^{3}$ Two third of this disease cases i.e. nearly 5 to 6 million cases occur in the age group between 15 to 49 years, with significant socioeconomic impact. In India, burden of this disease is heightened by the fact that more than $40 \%$ of population is infected with TB bacilli. Severity can be judged by the fact that approximately 18 lakh people develop $\mathrm{Tb}$ and nearly 4 lakh die from it every year in India. India accounts for one fifth of the global incidence of tuberculosis and tops the list of twenty two high tuberculosis burden countries . ${ }^{4}$ In India, both incidence and mortality of tuberculosis is highest among the adults aged 15 to 60 years. ${ }^{4}$

Recent data showed that in 2005, 8.8 million new TB cases were detected with $84 \%$ of them living in sub-Saharan Africa and Asia continent.
Approximately 1.6 million people gets infected by tuberculosis, including 1,95,000 patients gets coinfected with the human immunodeficiency virus. ${ }^{5}$ According to one of the report prepared by WHO (World Health Organization) in 1990, Tuberculosis was ranked seventh amongst diseases causing morbidity and predicted that it would retain its position in 2020 also. $^{6}$

It has also been reported that in every four seconds one person gets infected by tuberculosis anywhere in the world and one of them succumbs to it in every ten seconds. ${ }^{7}$ Data revealed that in 2006 , treatment was given to 1.4 million cases of tuberculosis and among these about $28.7 \%$ people were categorized as new sputum smear negative tuberculosis cases. ${ }^{8}$

TRC estimated that around 3.8 million (95\% C.I: 2.8-4.7) bacillary pulmonary tuberculosis cases and 12.9 million (95\% C.I: 9.7-16.0) smear as well as culture negative cases in whom chest $\mathrm{x}$-ray were found abnormal. The "chest x-ray abnormal" include patients who have negative sputum by smear as well as culture, but whose chest x-ray was read by two independent readers as possible or probable tuberculosis. ${ }^{9}$

Under the programme, those endorsed by World Health Organization, and implemented in high burden countries successfully, the diagnosis of PTB is based on sputum smear examination under India's Revised National Tuberculosis Control Programme (RNTCP). ${ }^{10,11}$

The main methods to diagnose pulmonary tuberculosis are chest x-ray, sputum smear microscopy and culture of Mycobacterium tuberculosis bacilli. Among these, sputum microscopy is the primary method to diagnose tuberculosis, as it is less expensive, more specific as it has less inter-reader variability than chest $\mathrm{x}$ ray.

In our study, we are going to evaluate the clinical symptoms and presentation of tuberculosis of adult patients in Chest X-ray for early detection of this disease and proper management. 


\section{Material and Method}

The cross-sectional retrospective study was conducted at respiratory department of a tertiary care centre in Rajasthan, on 197 patients, where data was collected from year 2019 to 2020 from tuberculosis register maintained in tuberculosis unit .

A physical examination along with a detailed clinical history was done in all patients. History of past TB or contact with TB, Bacille CalmetteGuérin (BCG) vaccination was noted. Investigations such as hemogram, TST by Mantoux test (5 TU), erythrocyte sedimentation rate (ESR), chest X-ray, and liver enzyme estimation were done.

Patients who were more than 15 years regardless of gender, clinical history and chest X-Ray suggesting pulmonary tuberculosis were included in this study. Patient who had severe dyspnoea, unstable cardiovascular status, uncooperative and extrapulmonary tuberculosis were excluded from this study. Patients with drug resistant tuberculosis were not taken into consideration for present study. Standard definitions used in RNTCP were used for diagnosis.

Informed consent was taken from all the patients before starting this study. Ethical clearance from institute was taken.

\section{Result}

A total of 197 patients were studied who fulfilled the inclusion criteria were enrolled in this study from January 2019 to June 2020. This study was done in Department of Respiratory medicine in a tertiary care hospital, Rajasthan.

Selection criteria of cases of this study was based on history, physical examination, chest X-ray findings and sputum smear negativity for AFB bacilli which were suggested of pulmonary tuberculosis.

Patients of both gender aged fifteen years or above were selected for the study. After proper history taking, physical and clinical examination and radiological examination (chest X-ray), the presumptive diagnosis of pulmonary tuberculosis was made.

In this study, out of 197 patients, 144 were male (73.1\%) and 53 were females (26.9\%) as shown in Table 1. 137 ( $69.5 \%)$ patients were of age group 21-40 years and only $16(8.13 \%)$ patients between 61-70 years (table 2). Out of 197 patients, 152 were of rural area $(77.2 \%)$ and 45 were of urban area (22.8\%) as shown in table 3.

Table 1: Gender distribution of the population

\begin{tabular}{|l|c|c|}
\hline Gender & Total Number of Cases & Percentage \\
\hline Male & 144 & 73.1 \\
\hline Female & 53 & 26.9 \\
\hline Total & 197 & 100 \\
\hline
\end{tabular}

Table 2: Age and Sex distribution of the population

\begin{tabular}{|l|c|c|c|c|c|c|}
\hline Age in years & Total cases & Percentage & Male & Percentage & Female & Percentage \\
\hline $11-20$ & 8 & 4.06 & 0 & 0 & 8 & 16.6 \\
\hline $21-30$ & 84 & 42.7 & 62 & 41.6 & 22 & 45.8 \\
\hline $31-40$ & 53 & 26.9 & 41 & 27.5 & 12 & 25 \\
\hline $41-50$ & 11 & 5.6 & 11 & 7.4 & 0 & 0 \\
\hline $51-60$ & 25 & 12.7 & 22 & 14.8 & 3 & 6.25 \\
\hline $61-70$ & 16 & 8.13 & 13 & 8.7 & 3 & 6.2 \\
\hline Total & 197 & 100 & 149 & 100 & 48 & 100 \\
\hline
\end{tabular}

Table 3: Area wise distribution of study population

\begin{tabular}{|l|c|c|}
\hline Area & Total Number of Cases & Percentage \\
\hline Rural & 152 & 77.2 \\
\hline Urban & 45 & 22.8 \\
\hline Total & 197 & 100 \\
\hline
\end{tabular}


Table 4: Symptoms at presentation in the study group

\begin{tabular}{|l|c|c|}
\hline Symptoms & Number of Cases & Percentage \\
\hline Cough/expectoration & 174 & 88 \\
\hline Fever & 169 & 85.7 \\
\hline Haemoptysis & 76 & 38.5 \\
\hline Chest pain & 34 & 17.2 \\
\hline Shortness of breath & 2 & 11.1 \\
\hline Heaviness of chest & 6 & 3.0 \\
\hline
\end{tabular}

Table 5: Frequency of chest radiological pattern in study group

\begin{tabular}{|l|c|c|}
\hline Radiological pattern & Frequency & Percentage \\
\hline Pulmonary infiltrate & 110 & 55.8 \\
\hline Cavity & 59 & 29.9 \\
\hline Nodular shadow & 17 & 8.7 \\
\hline Miliary pattern & 11 & 5.6 \\
\hline Total & 197 & 100 \\
\hline
\end{tabular}

Table 6: Distribution of site of lesion in the study group

\begin{tabular}{|l|c|c|}
\hline Site of involvement & Total number of case & Percentage \\
\hline Unilateral & 163 & 82.7 \\
\hline Bilateral & 34 & 17.3 \\
\hline Total & 197 & 100 \\
\hline
\end{tabular}

Table 7: Frequency of extent of involvement $n$ chest xray of the study group

\begin{tabular}{|l|c|c|}
\hline Extent of involvement in chest X-ray & Number of cases & Percentage \\
\hline Right upper zone & 118 & 59.8 \\
\hline Left upper zone & 23 & 11.6 \\
\hline Right mid zone & 17 & 8.8 \\
\hline Left mid zone & 3 & 1.5 \\
\hline Lower lung field & 8 & 4.0 \\
\hline Diffuse parenchymal involvement & 28 & 14.3 \\
\hline Total & 197 & 100 \\
\hline
\end{tabular}

In our study, cough was the most common symptom $(88.0 \%)$ followed by fever $(85.7 \%)$. Hemoptysis $(38.5 \%)$ and chest pain $(17.2 \%)$ were the next common symptoms. Heaviness of chest (3.0\%) was the least common symptom (table 4). Pulmonary infiltrate $(55.8 \%)$ was most common radiological finding in their chest $\mathrm{x}$-ray, followed by cavity (29.9\%). 17 patients had nodular shadow (8.7\%) and only 11 patients had military pattern $(5.6 \%)$ (table 5).

In our study, out of 197 cases, 163 patients had unilateral involvement of lung (82.7\%) and only 34 cases had bilateral involvement (17.3\%) (table 6). Most of the patients had right upper zone (59.8\%) involvement, followed by left upper zone $(11.6 \%)$ with involvement of lower lung field in only $4.0 \%$ (table 7 ).

\section{Discussion}

In our study, male patients outnumbered female patients. All patients with age from 15-70 years were included in this study with 142 males and 48 females. No definitive data regarding gender involvement is available till date but a study done in Brazil and majority of authors showed greater incidence of sputum positive pulmonary tuberculosis in males only ${ }^{12,13}$. So our study showed of sputum smear negative cases shows similar result of gender involvement in sputum smear positive cases.

Tuberculosis is common among elderly in developed countries, but in developing countries it involves younger population. In recent time, trend towards increasing age being significant when compared to 20 years ago. ${ }^{14}$ In Scotland, in 1993, $64 \%$ of patients of tuberculosis were of age over 
55 years, as compared to Asian patients where $85 \%$ were under 55 years. ${ }^{15}$

A study done in Pakistan, involving 5023 Pulmonary Tuberculosis cases, showed Tuberculosis mainly affects people between 15 to 59 years of age, accounting $75 \%$ of the cases ${ }^{16}$. In our study least age involved was of 18 years with highest being 70 years.

This study showed higher prevalence in the rural population $(80 \%)$ then in urban population (20.0\%). This data is similar with the findings of National Family Health Survey (NFHS-3) which showed higher prevalence in rural area (469 vs. 307 per 100000 population).$^{17}$

A study did by Raina et al ${ }^{18}$ showed poverty, illiteracy etc to be a major factor for developing tuberculosis in rural population. In rural population overcrowding also contribute a role.

Individuals with pulmonary tuberculosis who come to hospitals to seek treatment presents with symptoms like cough in $70-90 \%$, fever $15-52 \%$, weight loss in $43-75 \%$, haemoptysis among 21 $29 \%$ and fatigue and malaise in $58 \% .^{19,20,21,22,23}$

In our study cough (88\%) followed by fever $(85.7 \%)$ was the most common symptoms. Other studies done showed fever is the most common symptom. Fever in patients with tuberculosis varies from 37 to $80 \%$ as shown in different studies. $^{24,25}$ In one study, it showed $21 \%$ of patients had no fever in the entire hospitalization period for tuberculosis ${ }^{26}$. In other studies it showed cough is the most frequent symptom. ${ }^{26,27}$ In this study we found pulmonary lesions in all of the cases. Among these, pulmonary infiltrate was most common finding. Even though in our study pulmonary infiltrate was present in $54.2 \%$ of cases but when cavity lesions gets combined by pulmonary infiltrate lesions, it accounts for $85.4 \%$ cases. In a study done by Aktogu et $\mathrm{al}^{23}$ also showed pulmonary infiltrate as most common finding (in $99.0 \%$ of total cases).

In chest $\mathrm{x}$-ray when cavities are present, it $\mathrm{s}$ considered as an important radiological evidence to suspect tuberculosis in adults. ${ }^{28}$ In literature , frequency of appearance of cavity in chest varies from $40-80 \%{ }^{23,29,30}$ In our study, cavity lesion was present in $31.2 \%$ of cases. A study done by Nyman et $\mathrm{al}^{31}$ showed cavities in $13.9 \%$ of their 215 cases.

The nodular form is found in of least number of cases of tuberculosis in adults, it may calcify in time. In study done by Nyman et al ${ }^{31}$ showed $7 \%$ of 214 cases. In other study done by Khan et al ${ }^{32}$ showed nodular lesions in $9 \%$ of 88 cases of pulmonary tuberculosis. In our study, we did not found any lymphadenopathy in the chest $\mathrm{x}$-ray of any case.

In our study, miliary pattern was present in 5.7\% of the total cases. Miliary form may present in post primary cases also in $7 \%$ of cases. ${ }^{33,34}$

In studies done in 204 and 500 cases, the site of cavity lesion were found to involve posterior and or apical segments of upper lobe in $83 \%-85 \%$ cases and superior segment of lower lobe was involved in $11 \%$ - $14 \%$ cases. ${ }^{34,35}$. In majority of cases , parenchymal involvement was present. ${ }^{36,37}$ In our study, right upper zone was involved in $58.4 \%$ cases. Diffuse parenchymal involvement was seen in $14.7 \%$ cases and lower lung field was involved in only $4.2 \%$ of cases.

In countries where prevalence of tuberculosis is high, like India, patients who have pulmonary lesions suggestive of tuberculosis but are AFB sputum negative should be treated with antitubercular drugs. This can be helpful in most of the cases as it avoid invasive diagnostic procedure in future. But this approach can lead to poor outcome if started in non-tuberculosis patients like in bronchogenic carcinoma.

\section{Conclusion}

Pulmonary tuberculosis is more common in males then female. Most of the patients were of age group 21-40 years and only 16 patients between 61-70 years. Cough was the most common symptom followed by fever, hemoptysis and chest pain. Most of the patients had right upper zone involvement followed by left upper zone. Pulmonary tuberculosis is a curable disease if given proper treatment at proper time. Clinician 
need to understand these symptoms and findings of Chest X-ray soon for better management of patients. More study need to be done including different data from various tertiary care centre for more specific details.

Financial Support: None as stated by author

Conflict of Interest: None as stated by author

\section{References}

1. Brett-Major DM, Walsh TE. Laboratory Diagnosis of Tuberculosis in Primary Care. Dis Mon 2006; 52:450-458.

2. Chin NK, Kumarashinge G, Lim TK. Efficacy of the conventional diagnostic approach to pulmonary tuberculosis. Singapore Med J 1998; 39:241-246.

3. Dunlap NE et al. Diagnostic Standards and Classification of Tuberculosis in Adults and Children. Am J Respir Crit Care Med 2000; 161:1376-1395.

4. Managing the Revised National Tubercuosis Control Programme in your area. Modules 1-4, Central TB Division, Directorate General of Health Services, Ministry of Health and Family Welfare: P.1-3.

5. World Health Organization. Global tuberculosis control surveillance, planning, financing. WHO Report 2007.Geneva: World Health Organization; 2007.WHO/HTM/TB/2007.376.

6. Murray CJL, Lopez AD. The Global burden of disease: A comprehensive assessment of mortality and disability from diseases, injuries, and risk factors in 1990 and projected to 2020: Summary. Geneva:World Health Organization;1996.p.41.

7. Dye C, Scheele S, Dolin P, Panthania V, Raviglione MC. Global burden of tuberculosis: Estimated incidence, prevalence, and mortality by country. WHO Global Surveillance and Monitoring Project. JAMA 1999; 282:677-686
8. Ministry of Health and Family Welfare, Directorate General of Health Services, Central TB Division.TB India: RNTCP status report. Chapter 7, Performance of RNTCP.2007.p.71-106.

9. Meeting of the Expert Committee to Estimate TB Burden in India; 10-1 $1^{\text {th }}$ March 2005, New Delhi.

10. World Health Organization, Stop TB Department. Treatment of Tuberculosis: Guidelines for National Programmes; 3rd edn.Geneva: World Health Organization; 2003.WHO/CDS/TB/2003. 313.

11. TB India 2007. RNTCP Status Report. New Delhi: Central TB Division, Directorate General of Health Services, Ministry of Health and Family Welfare, Government of India;2007.

12. Gomes M, Saad Jr R, Stirbulov R. Pulmonary tuberculosis- Relationship between sputum bacilloscopy and radiological lesion. Rev Inst Med Trop S Paulo 2003; 45(5):275-281

13. Kritski AL, Conde MB, Souza GRM. Tuberculose: do ambulatório àenfermaria. 2. ed. São Paulo, Atheneu. 2000.

14. Goldstein RS, Contreras M, Craig GA, Cheung OT. Tuberculosis: a review of 498 recent admissions to hospital. Can Med Assoc J 1982; 126: 490.

15. Leitch AG, Rubilar M, Curnow J, et al. Scottish National Survey of tuberculosis notifications, 1993, with special reference to the prevelance of HIV seropositivity. Thorax 1996; 51:78.

16. Ansari A. TB is a disease of young people in province of Sindh. Analysis of 5023 TB cases. Proceedings of $1^{\text {st }}$ Biennial conference on chest diseases and TB. Peshawar, Pakistan. March 1994:49.

17. International Institute for Population Sciences (IIPS) and Macro International (2005-2006) National Family Health Survey (NFHS-3), India: Volume I. Mumbai:IIPS,2007. 
18. Raina RK, Kaul S, Smgh A, et al ." Prevalence of TB in Kishtwar Tehsil of Jammu region in J\&K State" . J Ind Med Asso 1996; 94(9):334.

19. Barnes PF, Verdegem TD, Vachon LA, et al. Chest roentgenogram in pulmonary tuberculosis. New data on an old test. Chest 1988; 94(2):316-320.

20. Morris CD, Bird AR, Nell H. The haematological and biochemical changes in severe pulmonary tuberculosis. Q J Med 1989; 73(272):1151-1159.

21. MacGregor RR. A year's experience with tuberculosis in a private urban teaching hospital in the postsanatorium area. Am J Med 1975; 58(2):221-228.

22. Miller LG, Asch SM, Eu EL, et al. A population-based survey of tuberculosis symptoms: how atypical are atypical presentations? Clin Infect Dis 2000; 30(2):293-299.

23. Aktogu S, Yorgancioglu A, Cirak K, et al. Clinical spectrum of pulmonary and pleural tuberculosis: a report of 5,480 cases. Eur Respir J 1996; 9(10):20312035 .

24. Arango L, Brewin AW, Murray JF. The spectrum of tu-berculosis as currently seen in a metropolitan hospital. Am Rev Respir Dis 1978; 108:805-812.

25. Kiblawi, S S O, Jay SJ, Stonehill RB, Norton J. Fever response of patients on therapy for pulmonary tuberculosis. Am Rev Respir Dis 1981; 123:20-24.

26. Bass JR Jr, Farer LS, Hopewell PC, Jacobs RF, Snider DE Jr. Diagnostic standards and classification of tuberculosis. Am Rev Respir Dis 1990; 142:725-735.

27. Hopewell PC. A clinical view of tuberculosis. Radiol Clin North Am 1995; 33:641-653.
28. Pratt PC. Pathology of tuberculosis. Semin Roentgenol 1979; 14:196- 203.

29. Bonadio M, Spitaleri P, Gigli C, et al. Current epidemiological and clinical aspects of tuberculosis: a study in the Hospital of Pisa. Recenti Progr Med 2000; 91:347-351.

30. Buckner CB, Walker CW. Radiologic manifestations of adult tuberculosis. $\mathrm{J}$ thorac Imag 1990; 5:28-37.

31. Nyman RS, Brismar J, Hugosson C, Larsson SG, Lundstedt C. Imaging of tuberculosis: experience from 503 patients. I. Tuberculosis of the chest. Acta radiol (Stockh) 1996; 37:482-488.

32. Khan MA, Kovnat DM, Bachus B, et al. Clinical and roentgenographic spectrum of pulmonary tuberculosis in the adult. Amer J Med 1977; 62: 31-38.

33. McAdams HP, Erasmus J, Winter JA . Radiologic manifestations of pulmonary tuberculosis. Radiol Clin N Amer 1995; 33:655-678.

34. Sweany HC, Cook CE, Kegerreis R. A study of the position of primary cavities in pulmonary tuberculosis. Am Rev Tuber 1931; 24:558-582.

35. Poppius H, Thomander K. Segmentary distribution of cavities: a radiologic study of 500 consecutive cases of cavernous pulmonary tuberculosis. Ann Med Interne Fenn 1957; 46:113-119.

36. Morris JT, Seaworth BJ, McAllister CK. Pulmonary tuberculosis in diabetics. Chest 1992; 102:539-541.

37. Woodring JH, Vandiviere HM, Fried AM, Dillon ML, Williams TD, Melvin IG. Update: the radiographic features of pulmonary tuberculosis. AJR 1986; 146:497-506. 